\title{
PENGEMBANGAN KAMPUS BNGKEL TEATER W.S RENDRA DI KOTA DEPOK DENGAN PENDEKATAN ARSITEKTUR NEO VERNAKULAR
}

\author{
Ahmad Rizky Chaidir ${ }^{1}$, Karya Widyawati ${ }^{2}$, Nia Suryani ${ }^{3}$ \\ ${ }^{1}$ Universitas Indraprasta PGRI, Program Studi Arsitektur \\ rizkyhaidir22@gmail.com \\ ${ }^{2}$ Universitas Indraprasta PGRI, Program Studi Arsitektur \\ karya.widyawati@unindra.ac.id \\ ${ }^{3}$ Universitas Indraprasta PGRI, Program Studi Arsitektur \\ niasuwardi@gmail.com
}

\begin{abstract}
The development of the W.S Rendra Theater Workshop campus in Depok City with a Neovernacular Architectural Approach, which is a cultural heritage building developed by the writer Dr. Willibrordus Surrendra Broto Rendra, SS., M.A or known as W.S Rendra. The theater workshop itself acts as a forum for preserving theater arts for artists as well as the public and students. A place that provides training facilities for dance studios, theaters, cultural arts events is very influential for the local community, by applying the Neo Vernacular Architecture approach with local cultural nuances that produces a source of knowledge of cultural arts and the harmony of each local culture in the WS Theater Workshop building Rendra, it is necessary to have a harmonious concept in order to achieve a building that is able to provide teaching and harmony to the surrounding building area.
\end{abstract}

Key Words: Theater Workshop, Studio, Cultural Reserve, W.S Rendra Theater.

\begin{abstract}
Abstrak : Pengembangan kampus Bengkel Teater W.S Rendra di Kota Depok Dengan Pendekatan Arsitektur Neovernakular yaitu suatu bangunan cagar budaya yang kembangkan oleh sang Sastrawan Dr. Willibrordus Surrendra Broto Rendra, SS., M.A atau di kenal sebagai W.S Rendra. Bengkel Teater itu sendiri berperan sebagai wadah perestarian seni theater bagi seniman maupun masyarakat dan pelajar. Wadah yang menyediakan sarana pelatihan sanggar tari, theater, event-event kebudayaan seni sangat berpengaruh bagi masyarakat local, dengan menerapkan pendekatan Arsitektur Neo Vernakular yang bernuansakan budaya local setempat yang menghasilkan sumber ilmu pengetahuan seni budaya dan kerharmonisan setiap budaya local setempat dalam bangunan Bengkel Teater W.S Rendra ini, perlu adanya konsep yang selaras agar tercapai suatu bangunan yang mampu memberikan pemberajaran dan keharmonisan pada wilayah bangunan sekitar.
\end{abstract}

Kata Kunci : Bengkel Teater, Sanggar, Cagar budaya, Teater W.S Rendra.

\section{PENDAHULUAN}

Indonesia terkenal dengan kekayaan budayanya, terdapat 300 etnis, 1200 bahasa dan 1300 suku bangsa didalamnya (Badan pusat statistic,2010). Keanekaragaman budaya dari beberapa suku yang sangat besar,sehingga menyebabkan Indonesia kaya akan budaya. Seperti hal nya Kota Jakarta dan Kota Depok yang memiliki perbedaan budaya, Kota Depok senidiri berasal dari Suku Betawi dan Sunda. Perbedaan ini menjadikan Kota Depok kental akan budayanya mulai dari seni tari, tari topeng, lenong, pancaksilat, music tradisonal Sunda, music tradisonal Betawi dan masih banyak yang lainnya.
Seni kebudayaan yang dulu mudah dikenali dari banyak hal salah satunya adalah seni pertunjukan dimana seni pertunjukan itu sendiri menampung hampir keseluruhan seni termasuk seni tari, seni musik, seni teaterikal, dan lain sebagainya. Hal ini menyebabkan seni pertunjukan dapat menjadi suatu wadah pengembangan kebudayaan yang edukatif, informatif namun juga sebagai wahana hiburan, membuat banyak orang dapat melestarikan kebudayaan dengan cara yang mudah dan menarik.

Namun akhir-akhir ini Kota Depok mulai terpengaruhi oleh era globalisasi, yang saat ini mulai berkembangan pesat. Mulai dari 
perkembangan di bidang ilmu pengetahuan dan teknologi, hingga kebudayaan sekaligus. Hal ini berdampak besar bagi gaya hidup masyarakat

Indonesia yang mulai beralih kebaratbaratan dan mulai meninggalkan kebudayaan asli. Begitu prihatin jika melihat seni pertunjukan tradisional saat ini hanya sedikit orang yang meminatinya daripada seni pertunjukan yang modern dan glamor.

Di erasekarag pertunjukan seni tari tradisional kalah tersaingi dengan modern dance dari Korea atau yang sering disebut "K-pop". Tidak hanya seni tari, seni pertunjukan drama juga mengalami penurunan seiring berjalannya waktu. Contohnya seperti pertunjukan ketoprak, ludruk,lenong, wayang dan lain-lain.

Banyak sekali anak-anak muda di Kota Depok ini lebih meminati pertunjukan yang modern daripada pertunjukan tradisional. Seni tari dan derama tradisional ditinggalkan karena dianggap kampungan dan tidak sejalan dengan gaya hidup anak muda masa kini. Hal ini dibuktikan dengan kurangnya partisipasi anakanak muda dalam mengikuti seni tari tradisional.

Sampai saat ini belum ada suatu media atau tempat yang menarik untuk mengembangkan budaya seni tradisonal ini, sehingga masyarakat di Depok sangat perlu adanya tempat untuk lebih menjadikan sarana edukasi dan pelestarian budaya seni.

Di Kota Depok sendiri masih ada salah satu tempat pelestarian kesenian yang masih aktif saat ini tetapi minat masyarakan saat ini yang sudah berkurang terhadap pelestarian seni tersebut, pada tempat tersebut berlokasi di Jalan Raya Cipayung Kota Depok yang bernama Kampus Bengkel Teater W.S Rendra yang dimiliki oleh alm wilibrordus surendra Bawana rendra (W.S Rendra).W.S Rendara itu sendiri adalah sastrawan dan budayawan berkebangsaan Indonesia yang namanya sudah mendunia, bengkel teater yang didirikan dari sejak tahun 1985. Bengkel teater ini di isi oleh ribuan karya sastra dan selain itu sebagai bengkel sanggar drama dan tari. Setelah W.S Rendra wafat pada tahun 2009, warisan lokasi sanggar yang asri tersebut pernah diusulkan menjadi Cagar Budaya W.S Rendra pada pemkot Kota Depok, tetapi karna aktifitas budaya yang sekarang sudah semakin berkurang sehingga ada keinginan melestarikan dan mengembangkan lebih luas sehingga masyarakat lebih bersimpati akan adanya budaya seni di Kota Depok.

Keperihatinan saat ini menjadika sumber permasalahan untuk mengembangkan Kampus Bengkel Teater tersebut untuk lebih menarik lagi dan sekaligus mengenang kembali Alm.W.S Rendra agar tahapan ini sedikit bisa lebih merubahnya untuk memperkuat ketertarikan masyarakat terhadap seni kebudayaan kala ini dengan menampilkan Bengkel teater ini menjadi lebih modern, tetapi tidak menghilangkan unsurunsur local dan keasrian dari Bengkel Teater tersebut.

\section{METODOLOGI}

Metode yang digunakan dalam penelitian ini menggunakan metode Deskriptif. Metode ini berupa penelitian yang menghasilkan data deskriptif berupa fenomena sosial yang terjadai dari lokasi studi maupun lisan dari orang-orang atau perilaku yang dapat diamati dengan menggunakan pendekatan deduktif. Metode ini dalam pendekatan pengembangan Benkel Teater adalah sebagai acuan untuk menyusun landasan pengembangan dan progam pengembangan Bengkel Teater W.S Rendara, diantaranya ;

a. Pengumpulan data primer, meliputi ;

1. Rencana Tata Ruang dan Wilayah (RTRW) Depok 2010 mengenai wilayah Cipayung Kota Depok.

2. Studi literatur tentang pengembangan kawasan Cagar budaya di Kota Depok.

b. Pengumpulan data sekunder, antara lain;

1. Studi banding atau presedent arsitektur mengenai Bengkel Teater proyek sejenis.

2. Pengamatan langsung permasalahan di lapangan mengenai permasalahan yang terjadi saat ini di Kota Depok.

3. Pemanfaatan maksimal potensi di sekitar Bengkel Teater W.S Rendra ..

4. Pengamatan tentang perkembangan budaya saat ini di Kota Depok. 
16 Pengembangan Kampus Bengkel Teater W.S Rendra di Kota Depok Dengan Pendekatan Arsitektur Neo Vernakular

5. Menganalisa ketertarikan masyarakat mengenai seni budaya local .

\section{HASIL DAN PEMBAHASAN Pengertian dan Tujuan Pemanfaatan Bengkel Teater}

Bengkel adalah tempat (bangunan atau ruangan) untuk perawatan atau pemeliharaan, perbaikan, modifikasi. dan teater adalah sebuah seni drama yang menampilkan perilaku manusia dengan gerak, tari, dan nyanyian yang disajikan lengkap dengan dialog dan akting para pemainnya. Kata teater diambil dari bahasa Yunani, theatron, yang artinya tempat atau gedung pertunjukan.

Bengkel didalam banyak Literatur /pustaka , disebutkan bahwa "Bengkel" (Workshop) pada umumnya mempunyai dua arti yaitu :

1) Secara umum berfungsi sebagai tempat

2) service,repair; dan mintenance atau (Perawatan, Perbaikan, dan Pemeliharaan) yang konotasi artinya dapat dijelaskan sebagai berikut

a. Perbaikan : mengganti bagian yg aus/rusak agar tidak terjadi kesalahan.

b. Perawatan : agar tetap cantik dan berumur panjang.

c. Pemeliharaan : agar ber produksi secara effisien dan mampu beranak.

3) Secara khusus berfungsi mirip dengan suatu laboratorium tempat membuktikan kebenaran ilmu dan melahirkan teknologi. misal : Bengkel Teater ; Bengkel Pengrajin ; Workshop/seminar di hotel, dan Bengkel R \& D (Research and Development), (Koes Sulistiadji (05-06-2006) Teknologi Mekanisasi Pengelolaan UPJA (Manajemen Bengkel)

Adapun tujuan dan manfaat dalam pengembangan kampus bengkel Teater W.S Rendra di antara lain adalah:

1. Bertujuan untuk mengembangkan bangunan Bengkel Teater W.S Rendra sebagai Cagar Budaya di Kota Depok.

2. Untuk memperbarui kondisi bangunan bengkel teater sekarang ini untuk lebih menarik lagi dan terkesan modern,tanpa menghilangkan cirikhas bangunan lama

Manfaat
1. Bagi masyarakat sebagai berikut:

a) Memenuhi Manfaat kebutuhan masyarakat terhadap kehadiran suatu wadah.atau sarana Gedung cagar budaya yang memenuhi standart kualitas.

b) Untuk memberikan suatu sarana Rekreasi/hiburan bagi masyarakat sekitar cipayung dan juga khususnya di Jawa Barat .

2. Bagi pelajar dan Seniman sebagai berikut:

a) Memberikan wadah ilmu untuk belajar teatrikal, seni tari budaya bagi pelajar dalam belajar mendalami seni Teater dan tari.

b) sebagai tempat bagi komunitaskomunitas seni teater untuk saling meningkatkan apresiasi seni.

c) Sebagai referensi desain perancangan bangunan kesenian.

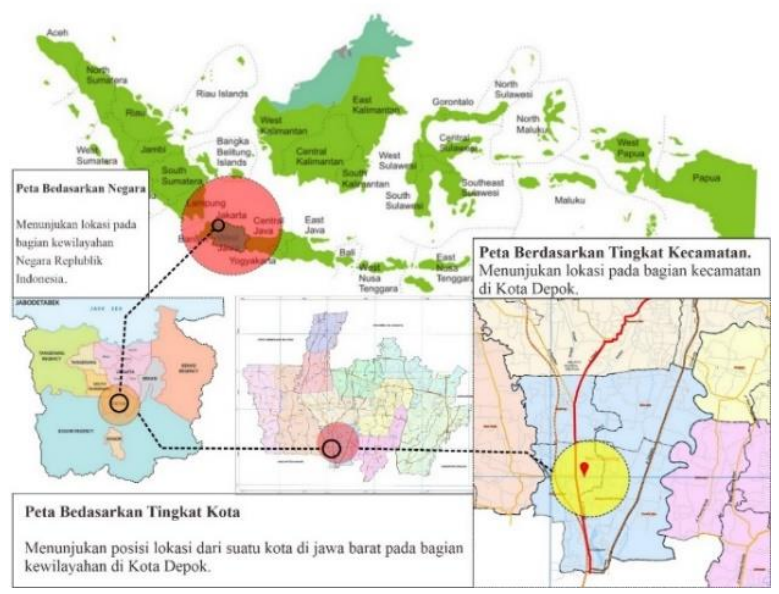

Gambar 1. Peta lokasi

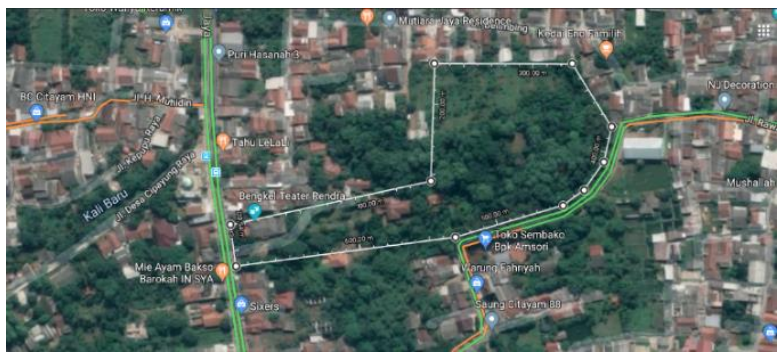

Gambar 2. Konteks Urban

\section{Konteks Urban}

Depok adalah salah satu dari 27 kota administrasi daro 18 kabupaten dan 9 Kota propinsi Jawa Barat. di sebelah utara Depok berbatasan dengan Bekasi . di sebelah timur berbatasan dengan karawang. di sebelah selatan 
berbatasan dengan Bogor Kota. di sebelah barat berbatasan dengan Kota Jakarta.(Badan Pemerintahan Kota Depok Kecamatan Cipayung Lokasi site berada di Kawasan Permukiman Komersil yang terintegrasi oleh permukiman penduduk dan askses utama, JL.Raya Cipayung yang terhubung dengan, JL.Raya Bojong gede. Dan di liputi oleh Jl.Tol Antasari Sawangan Depok.

Kelurahan ini memiliki kode pos 16436 16439, dan memiliki penduduk sebanyak 109.907 jiwa dan luas wilayah $1.091 \mathrm{Ha}$. wilayah ini berada pada titik koordinat antara $6^{\circ} 19^{\prime} 00^{\prime \prime}-6^{\circ} 28^{\prime} 00^{\prime \prime}$ Lintang Selatan dan antara $106^{\circ} 43^{\prime} 00^{\prime \prime}$ $106^{\circ} \quad 55^{\prime}$ 30" Bujur Timur. Secara geografis.(Badan Pemerintahan Kota Depok Kecamatan Cipayung )Dengan batas - batas wilayah adalah:

$\begin{array}{ll}\text { Utara } & \text { :Musholah An Nissa Jembatan } \\ & \text { Merah dan JL. Pitara Raya. } \\ \text { Selatan } & \text { : SMK Pariwisata dan } \\ & \text { JL.Kenarok. } \\ \text { Barat } & \text { : JL. Benda II dan JL. Keadilan } \\ \text { Timur } & \text { :JL.Raya Citayam. }\end{array}$

Ketentuan bangunannya sebagai berikut :

$\begin{array}{ll}\text { Luas lahan } & : 18000 \mathrm{~m}^{2} \\ \text { KDB } & : 45-60 \% \\ \text { KLB } & : 6\end{array}$

a. Lahan terbangun

: Luas lahan $\mathrm{x}$ KDB

: $18000 \mathrm{~m} 2 \times 45 \%$

: $8100 \mathrm{~m} 2$ (maksimal)

b. KLB

: KLB x Luas Lahan

: $6 \times 18000 \mathrm{~m} 2$

: $10800 \mathrm{~m}^{2}$

c. Lantai

: Lantai (maksimal)

: 2 lantai

\section{Metode Perancangan Desain}

Metode Pendekatan yang di gunakan untuk perkembangan Kampus Bengkel Teater ini yaitu pendekatan Arsitektur Neo-Vernakular yaitu merupakan suatu paham dari aliran Arsitektur Post-Modern yang lahir sebagai respon dan kritik atas modernisme yang mengutamakan nilai rasionalisme dan fungsionalisme yang dipengaruhi perkembangan teknologi industri. Arsitektur Neo-Vernakular merupakan arsitektur yang konsepnya pada prinsipnya mempertimbangkan kaidah-kaidah normative, kosmologis, peran serta budaya lokal dalam kehidupan masyarakat serta keselarasan antara bangunan, alam, dan lingkungan.

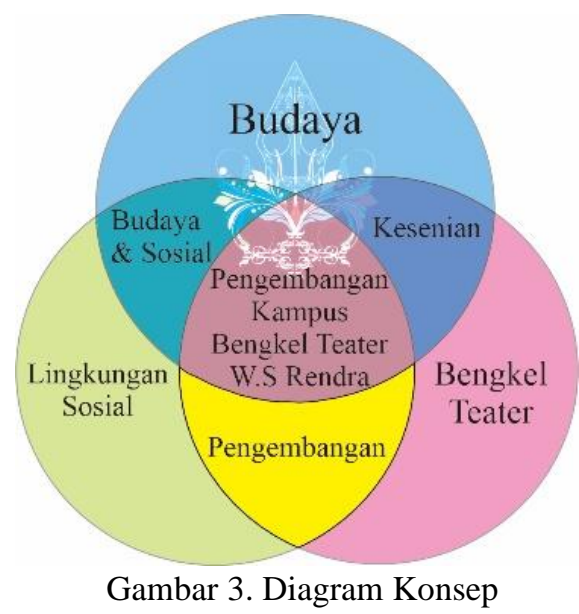

Tema

Tema pada pengembangan Kampus Bengkel Teater W.S Rendra, tema Arsitektur local dengan nuansa tiga budaya asli setempat yaitu Sunda, Betawi dan Jawa. Karena ingin mengangkat kebudayaan lokal setempat di Kawasan Kota Depok yang memiliki beberapa kearifan lokal. Selain kebudayaan setempat ke aslian seni Teater W.S Rendra yang mempunyai unsur nilai kekeluargaan, nilai budaya, nilai beragama, serta peristiwa sosial dan politik, menjadikan keaslian lokal setempat akan lebih lekat pada karakter si Kampus Bengkel Teater W.S Rendra tersebut.

Tema yang memadukan identitas Teater W.S Rendra dan arsitektur lokal yang menimbulkan persepsi kepada pengguna bahwa mereka akan merasa menikmati cirikhas, nuansa bahari dan kultural dalam kawasan tersebut dan membuat mereka akan menjadi mengenal dan mengingat kawasan tersebut dengan nuansa tematik yang tercipta.

\section{Tranformasi bentuk}

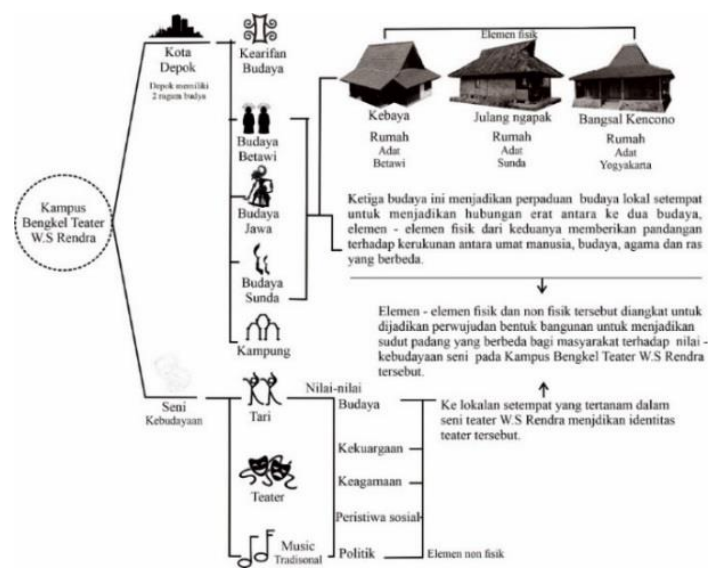

Gambar 4. Diagramatik konsep 
18 Pengembangan Kampus Bengkel Teater W.S Rendra di Kota Depok Dengan Pendekatan Arsitektur Neo Vernakular

Pembaharuan dan penerapan arsitektur local yang di dasari dari latar belakang Lokasi Bengkel Teater ini dari suku dan budaya pada Kota Depok, yang di latar belakangi dua perbedaan suku budaya yaitu Betawi dan budaya sunda, maka daritu perpaduan ini di jadikan sebagai trasnformasi bentuk untuk bagunan teater ini dengan mempadupadankan bangunan adat tradisonal Betawi dan rumah tradisonal sunda dengan pendekatan neo vernacular.

Tranformasi bentuk tebagi 2 pada bagian bangunan inti seperti Gallery, Pameran, Panggung Teatar dan Kediaman Rumah W.S Rendra.

\section{Tranformasi Teater}

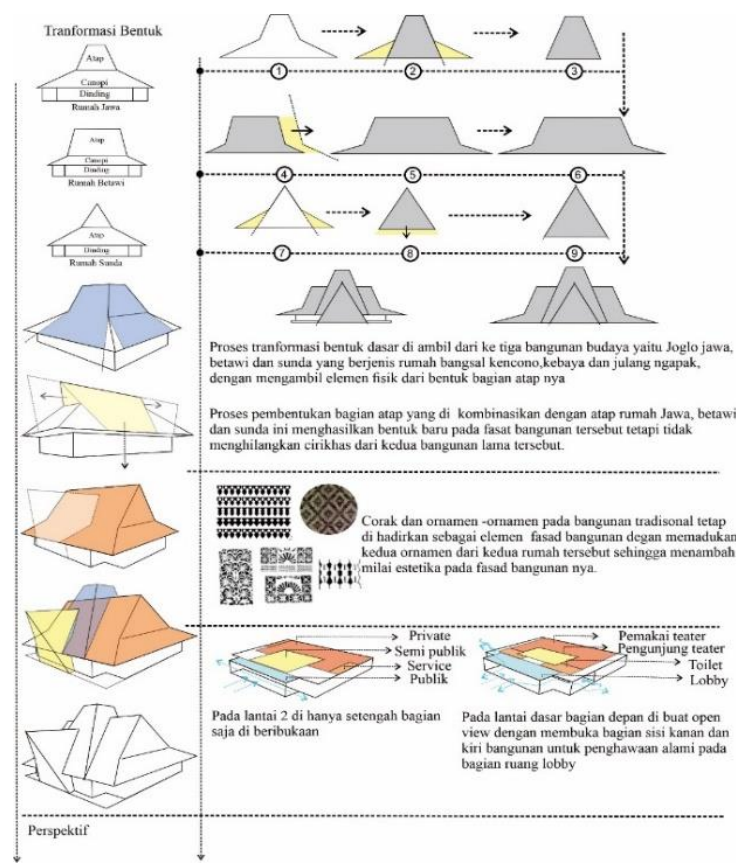

Gambar 5. Tranformasi bentuk Teater

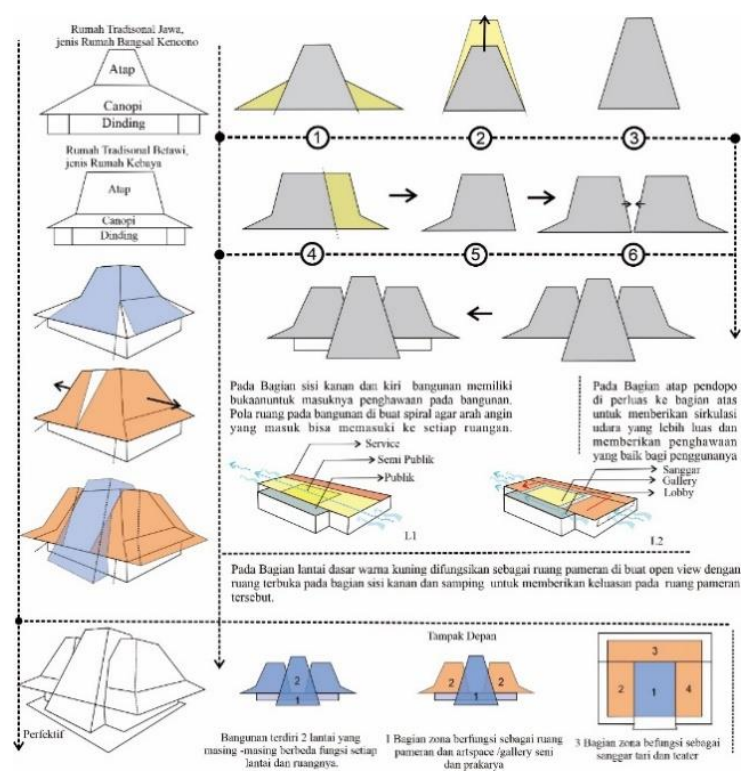

Gambar 6. Tranformasi Sanggar dan Gallery

Pada budaya dari rumah Tradisonal Jawa dan betawi memiliki Pendopo yang di filosofikan sebagai symbol bahwa mereka sangat terbuka untuk tamu yang ingin berkunjung. Filosofi ini berhubungan dengan makna yang erat pada kehidupan manusia. yaitu menjalani hubungan antara budaya yang berbeda dengan sesama.

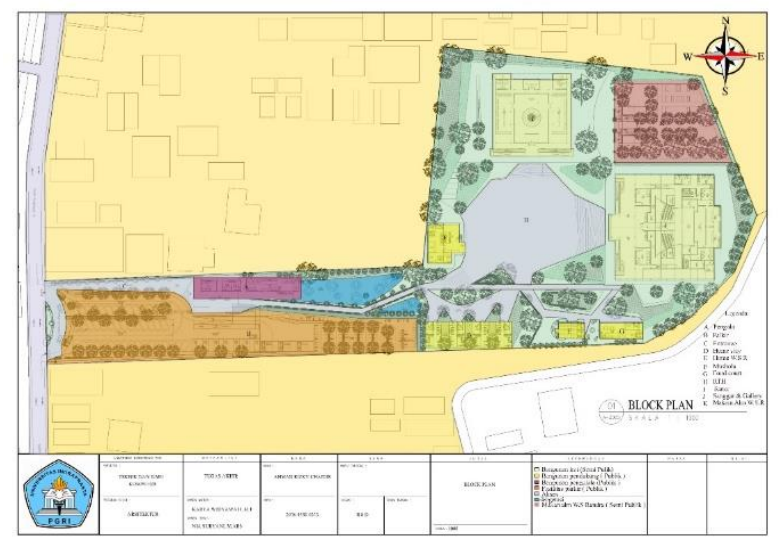

Gambar 7. Block Plan

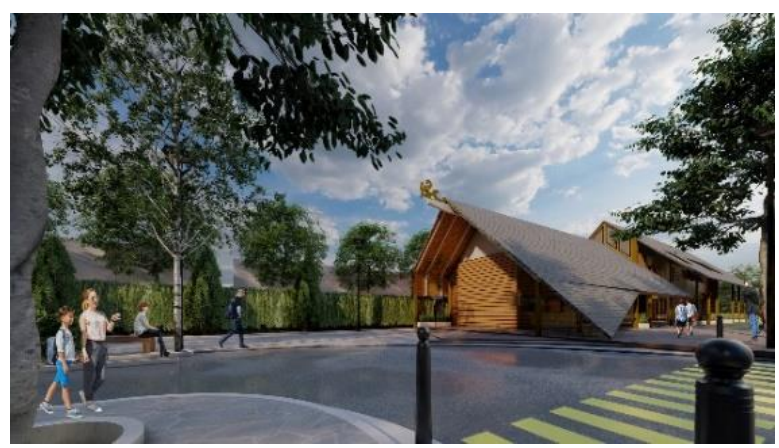

Gambar 8. Drof of area

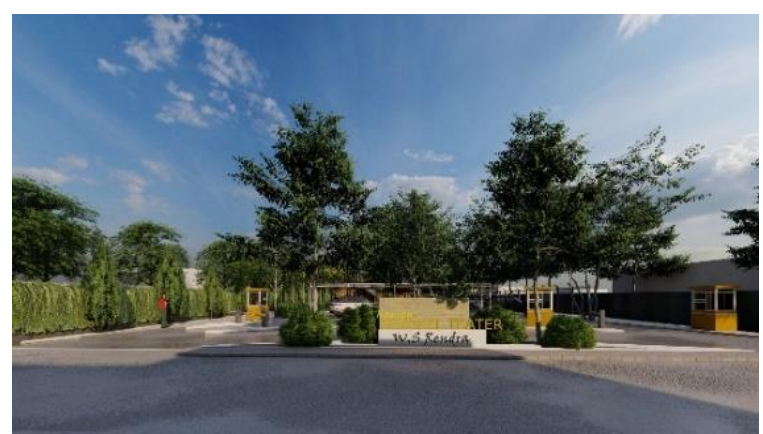

Gambar 9. Tampak Site 


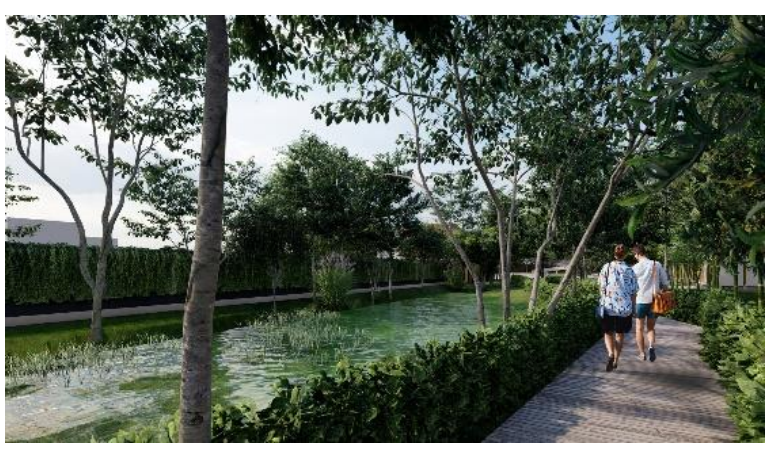

Gambar 10. Entrance

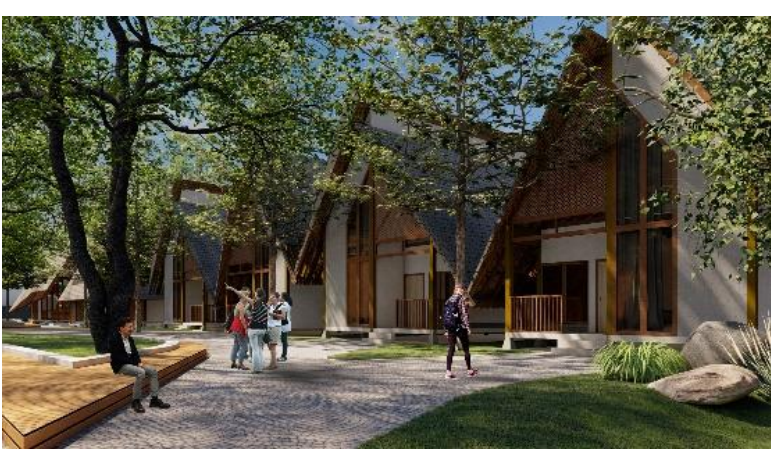

Gambar 11. Home Stay

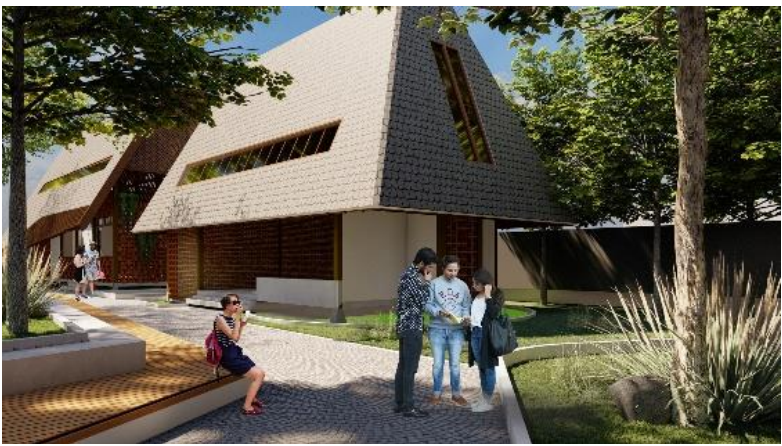

Gambar 12. Mushola

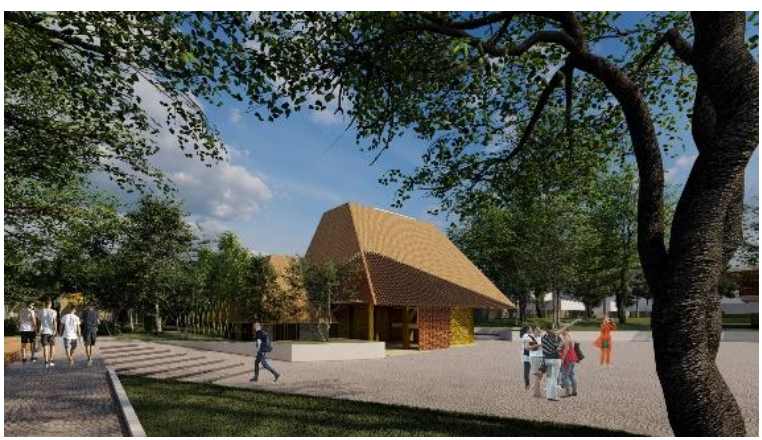

Gambar 13. Kediaman W.S Rendra

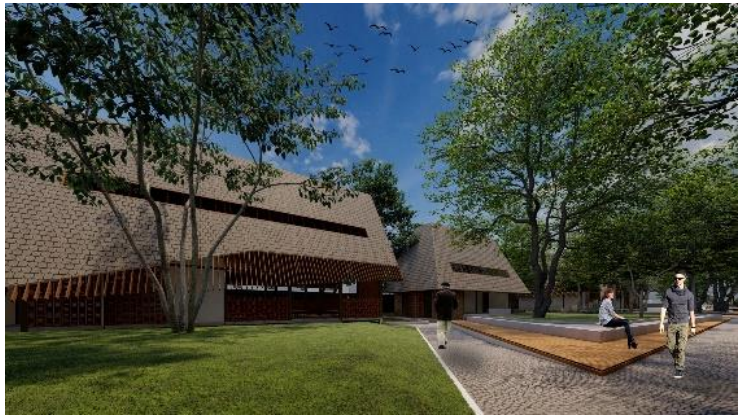

Gambar 14. Food court

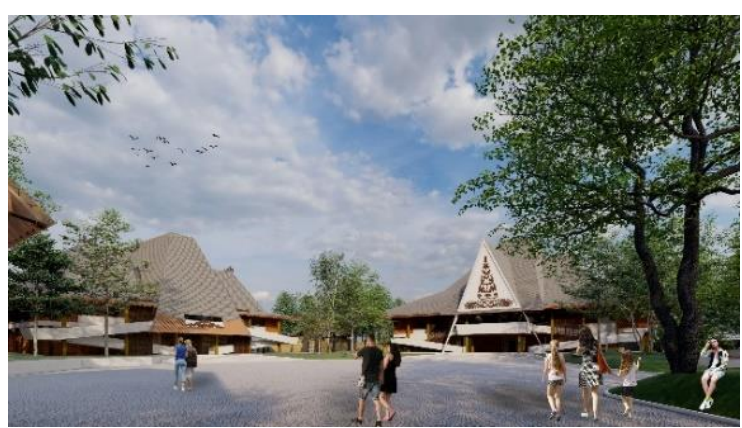

Gambar 15. Sanggar, Gallery dan Teater

\section{PENUTUP \\ Simpulan}

Kota Depok memiliki bergbagai macam suku,agama dan budaya di dalamnya mulai dari seni tari, tari topeng, lenong, pancaksilat, music tradisonal Sunda, music tradisonal Betawi. Namum berjalannya era globalisasi, yang saat ini mulai berkembangan pesat sangat berdampak besar bagi gaya hidup masyarakat sekarang, indonesia yang mulai beralih kebarat-baratan dan mulai meninggalkan kebudayaan asli. Begitu prihatin jika melihat seni pertunjukan tradisional saat ini hanya sedikit orang yang meminatinya daripada seni pertunjukan yang modern dan glamor.

Keperihatinan saat ini menjadika sumber permasalahan untuk mengembangkan Kampus Bengkel Teater W.S Rendra untuk lebih di minati bagi kalangan anak remaja dan bertujuan agar masyarakat tau akan pentingya nilai-nilai seni budaya pada pembelajaran generasi muda agar menciptakan generasi muda yang peduli akan kelestarian budaya lokal setempat denga nada nya Kampus Bengkel Teater W.S Rendra ini. 
20 Pengembangan Kampus Bengkel Teater W.S Rendra di Kota Depok Dengan Pendekatan Arsitektur Neo Vernakular

\section{Saran}

Berdasar kesimpulan di atas maka saran yang di perlukan yaitu untuk menyadari masyarakat akan kebudayan asli dan menjadikan sumber ilmu bagi generasi muda agar tetap mencintai budaya local dimbandingkan budaya asing. Dan saling melestarikan budaya lokal setempat dengan penampilan yang baru tanpa menghilangkan unsur kebudayaan tersebut.

\section{DAFTAR PUSTAKA}

Sam, U., \& Manado, R. (2011). Tinjauwan issn 2085-7020 Arsitektur 'Modern' ( Neo ) Vernakular di Indonesia Deddy Erdiono. 3(3), 32-39.

Alexander, N., Arifin, L. S., Arsitektur, P., Petra, U. K., \& Siwalankerto, J. (2014). Tradisonal Jawa di Surabaya. II(1), 44-51.

Santosa,Eko et al. 2008. Seni Teater Jilid 1-2 